\title{
Cryptococcosis of the central nervous system
}

\author{
Epidemiological, clinical, and therapeutic features
}

\author{
V. E. EDWARDS, J. M. SUTHERLAND, AND J. H. TYRER \\ From the Department of Neurology and the Medical Professorial Unit, Royal Brisbane Hospital, Brisbane \\ Australia
}

SUMMARY (1) A survey of cryptococcal infections of the nervous system in Queensland, Australia, revealed the nine year prevalence rate for the Australian aboriginal to be some 17 times greater than that of the white population. Uncommon in the first decade of life, the disease was developed by $79 \%$ of 29 patients between 20 and 59 years, males being affected twice as commonly as females. (2) Cryptococcosis appears to be more common in Australia than in the United Kingdom, and in Queensland the nine year incidence of neurological cryptococcosis was $4 \cdot 7$ per 100,000 in the tropical north compared with 1.8 per 100,000 in the southern parts of the State. Because of this, and since 20 of the 29 patients were regarded as having outdoor occupations, it is suggested that a high environmental exposure to the fungus may be associated with an animal reservoir and with dry, dusty conditions. It is also possible that geographical and occupational factors rather than racial predisposition account for the high incidence of the disease in the Australian aborigine. However, individual resistance and susceptibility are probably also important factors, since the clinical disease appears to be positively correlated with certain other diseases, or with steroid therapy, which would impair the immune responses of the body. (3) Headache is the outstanding symptom of neurological cryptococcosis and fever or evidence of meningeal reaction, though often present, may be absent. An awareness of the possibility of neurological cryptococcosis in the differential diagnosis of various intracranial disorders should lead to identification of the encapsulated C. neoformans in the cerebrospinal fluid. Although in eight of 26 patients the lumbar cerebrospinal fluid was sterile on repeated examination, in five cases $C$. neoformans was found on direct examination of cerebrospinal fluid obtained by ventricular puncture. The remaining three died before further investigations could be performed. (4) Before the introduction of amphotericin B, neurological cryptococcosis was almost invariably fatai. At the present time, the infection can be eradicated in some $80 \%$ of patients. Intravenous administration of amphotericin B is generally adequate, but the intrathecal route should be used for cases in relapse or in critically ill patients. In addition to the toxic effects of the drug, the possibility of later deterioration in the patient's condition due to meningeal reaction-for example, occult hydrocephalus-merits consideration and appropriate neurosurgical treatment.

Although relatively uncommon, cryptococcal infection of the nervous system is a grave disorder because of the high mortality rate, the risk of permanent damage to the nervous system, and the hazards associated with treatment. The aetiological agent (Cryptococcus neoformans, Torula histolytica) has been recovered from soil and from various animals and birds. Although it has a world-wide distribution, there are grounds for believing that the distribution of the yeast (or its virulence) is not uniform, and/or that there is variable susceptibility of populations at risk. Thus, MacGillivray (1966) reporting two cases of cryptococcal meningitis referred to the fact that 21 cases had been reported from the British Isles up to 1961 . On the other hand, in Australia where the vast majority of the population, although Australian born, is of British stock, some 100 cases of cryptococcosis have been reported in the literature since 1935. During this period the population of the British Isles has been four to five times that of Australia.

The present paper concerns a series of 29 patients 
who were diagnosed as suffering from cryptococcosis of the nervous system in Queensland, Australia, over the nine year period 1 November 1959 to 31 October 1968. Only one of these patients, a female who developed cryptococcal meningitis during a pregnancy, has been previously reported (Kuo, 1962). Certain epidemiological factors are discussed and reference is made to factors which may be important in the chain of aetiology. The clinical features of neurological cryptococcosis are reviewed with particular reference to early diagnosis. The efficacy and hazards of modern therapy are assessed.

\section{GEOGRAPHICAL NOTE}

The State of Queensland lies between $10^{\circ}$ and $29^{\circ}$ south latitude and $138^{\circ}$ and $154^{\circ}$ east longitude. Of its 667,000 square miles, approximately $54 \%$ lies within the tropical zone.

The mean population of Queensland for the survey period 1959 to 1968 has been estimated as being $1,598,150$, some $365,550(23 \%)$ living within the tropical zone. Brisbane, the state capital, has more than one-third of the state's population; otherwise the population is distributed mainly along the eastern seaboard (Fig. 1).
METHODS

Cryptococcosis is not a notifiable disease in Queensland; neurological cryptococcosis is a serious condition requiring specialized investigation and treatment, so that as a rule patients are ultimately admitted to one of the major hospitals at Brisbane, Cairns, Mount Isa, Rockhampton, Toowoomba, and Townsville. The records departments of these hospitals were contacted and then one of us (V.E.E.) visited these centres and studied the case histories and, when indicated, the necropsy reports of all patients found who had suffered from cryptococcosis of the nervous system over the period 1 November 1959 to 31 October 1968. We think that in this way practically all patients in Queensland who developed neurological cryptococcosis during the survey period have been documented. With one exception, all surviving patients have been personally examined by V.E.E. The remaining surviving patient now resident in Tasmania, was examined on our behalf by medical personnel of the Repatriation Department.

\section{RESULTS}

CLINICAL ASPECTS

CASE SERIES The case series is summarized in Table 1 and comprised 29 patients suffering from crypto coccosis of the nervous system.

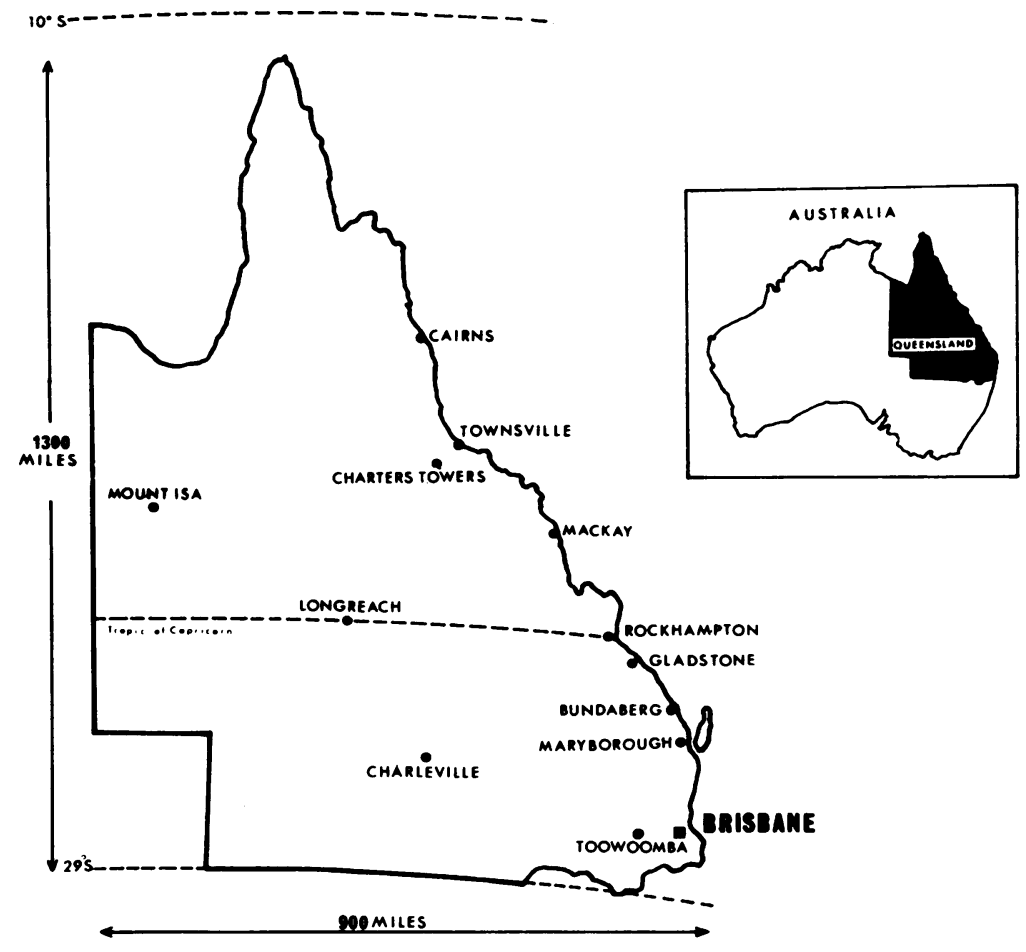

FIG. 1. Location of the cities and towns mentioned in the text. 
TABLE 1

CRYPTOCOCCOSIS OF THE NERVOUS SYSTEM

\begin{tabular}{|c|c|c|c|c|}
\hline $\begin{array}{l}\text { Total } \\
\text { series }\end{array}$ & $\overbrace{\substack{\text { males } \\
20}}^{\frac{29 \text { patients }}{9}}$ & $\begin{array}{l}\text { Diagnosed during life: } \\
\text { Post-mortem diagnosis: }\end{array}$ & 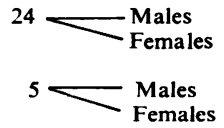 & $\begin{array}{r}18 \\
6 \\
2 \\
3\end{array}$ \\
\hline
\end{tabular}

SEX DISTRIBUTION In this series there were 20 male and nine female patients. Twenty-four patients (18 males and six females) were diagnosed during life as having cryptococcosis, while in five (two males and three females) the diagnosis was made at necropsy.

AGE DISTRIBUTION The ages of the 24 patients diagnosed as suffering from neurological cryptococcosis during life as well as the five patients in whom the diagnosis was made post-mortem are indicated in Table 2. Of the total series of 29 patients, $23(79.3 \%)$ developed the disease in clinical form between the ages of 20 and 59 years. We have knowledge of only one patient who developed neurological cryptococcosis in the first decade of life. This patient was an aboriginal boy who developed cryptococcal meningitis at 8 years of age while receiving steroid therapy for eosinophilic granuloma.

OCCUPATIONAL DISTRIBUTION The occupations of the 29 patients were divided summarily into outdoor and indoor work (Table 3). The figures for the number of people in each occupation are available only for the census years 1961 and 1966 and a mean over the nine years review period could not be obtained. Further, certain differences in definition of the work force in the two censuses made figures for 1961 and 1966 not strictly comparable. Finally, the small number of patients involved rendered any attempt at statistical interpretation of doubtful value. However, the types of work engaged in by the 20 patients regarded as having outdoor occupations and the total numbers thus employed in Queensland are detailed in Table 4.
TABLE 3

OCCUPATIONAL DISTRIBUTION

\begin{tabular}{lccccccc}
\hline & \multicolumn{2}{c}{ Diagnosed during life } & & Necropsy diagnosis & \\
& Male & Female & & Male & Female & Totals \\
\hline Outdoor occup. & 14 & 2 & & 2 & 2 & 20 \\
Indoor occup. & 4 & 4 & & - & 1 & 9 \\
Totals & 18 & 6 & & 2 & 3 & 29 \\
\hline
\end{tabular}

RAĊIAL DISTRIBUTION The population of Queensland (approximately 1.6 million) is predominantly of European extraction, the coloured population comprising only $19,300(1 \cdot 2 \%)$ of this total. In Table 5 the incidence of neurological cryptococcosis in these two racial groups is compared. The overall nine years ascertainment rate for Queensland was

TABLE 4

OCCUPATIONS OF OUTDOOR WORKERS WHO DEVELOPED NEUROLOGICAL CRYPTOCOCCOSIS

\begin{tabular}{|c|c|c|c|c|}
\hline \multirow[t]{2}{*}{ Type of occupation } & \multirow{2}{*}{$\begin{array}{l}\text { Occupation } \\
\text { code }\end{array}$} & \multirow{2}{*}{$\begin{array}{l}\text { Patients } \\
\text { (no.) }\end{array}$} & \multicolumn{2}{|c|}{$\begin{array}{l}\text { Total No. individuals } \\
\text { employed }\end{array}$} \\
\hline & & & $1961 \mathrm{Ce}$ & Census \\
\hline $\begin{array}{l}\text { Agricultural and farm } \\
\text { workers, drovers } \\
\text { Roadway building } \\
\text { earth-moving } \\
\text { Dairy farm workers } \\
\text { Waterside workers } \\
\text { Railway repairman } \\
\text { Sugar-cane grower } \\
\text { Poultry farmer }\end{array}$ & $\begin{array}{c}324 \\
761: 782 \\
326 \\
766 \\
772 \\
301 \\
311\end{array}$ & $\begin{array}{l}4 \\
3 \\
2^{*} \\
2 \\
1 \\
1\end{array}$ & $\begin{array}{r}12,605 \\
11,016 \\
7,238 \\
3,726 \\
5,267 \\
8,709 \\
892\end{array}$ & $\begin{array}{r}16,774 \\
6,794 \\
3,141 \\
4,488 \\
9,288 \\
911\end{array}$ \\
\hline
\end{tabular}

* One of these waterside workers was essentially engaged in handling livestock at the wharf.

TABLE 2

AGE DISTRIBUTION

\begin{tabular}{lccccccccc}
\hline & \multicolumn{7}{c}{ Years } & \\
\cline { 2 - 8 } & $<10$ & $10-19$ & $20-29$ & $30-39$ & $40-49$ & $50-59$ & $60-69$ & $70+$ & Totals \\
\hline $\begin{array}{l}\text { Diagnosed } \\
\text { during life (no.) }\end{array}$ & 1 & 2 & 7 & 5 & 1 & 5 & 3 & - \\
$\begin{array}{l}\text { Post-mortem } \\
\text { diagnosed (no.) }\end{array}$ & - & - & 2 & - & 1 & 2 & - & - \\
Totals & 1 & 2 & 9 & 5 & 2 & 7 & 3 & - \\
\hline
\end{tabular}


TABLE 5

RACIAL DISTRIBUTION

\begin{tabular}{lrrrrr}
\hline & $\begin{array}{c}\text { Patients } \\
\text { (no.) }\end{array}$ & Male & Female $\begin{array}{c}\text { Mean } \\
\text { population }\end{array}$ & $\begin{array}{c}\text { Nine years incidence } \\
\text { rate per 100,000 } \\
\text { of population }\end{array}$ \\
\hline $\begin{array}{l}\text { European } \\
\text { extraction }\end{array}$ & 24 & 17 & 7 & $1,578,850$ & \multicolumn{1}{c}{$1 \cdot 5$} \\
$\begin{array}{l}\text { Coloured } \\
\text { extraction* }\end{array}$ & 5 & 3 & 2 & 19,300 & 25.9 \\
Totals & 29 & 20 & 9 & $1,598,150$ & 1.8 \\
\hline
\end{tabular}

*Four patierits full or part Australian aboriginal: one patient Torres Strait Islander (Melanesian).

1.8 per 100,000 and for those of European extraction 1.5 per 100,000 . In comparison, five of the 29 patients in this series were coloured, furnishing a nine years rate of 25.9 per 100,000 for the coloured pepulation of the state.

GEOGRAPHICAL DISTRIBUTION In the present series of 29 patients, 22 were born in Queensland, 16 north of the Tropic of Capricorn, and six in Southern Queensland. Of the remainder, two patients were born in New South Wales, two in the United Kingdom, one in the Northern Territory, and one in Holland. In one instance the patient's birth place could not be traced.

Seventeen patients of the series developed neurological cryptococcosis while living in Queensland north of the Tropic of Capricorn, and 12 in Southern Queensland. This geographical distribution of the disease is shown in Table 6 and it will be seen that the nine years incidence rate in Northern Queensland is four to five times that of Southern Queensland.

CLINICAL SYNDROME Available evidence suggests that $C$. neoformans gains access to the body through the respiratory tract. The infection may then remain localized to the lungs or may spread to any part of the body and, in particular, to the nervous system. Cryptococcus neoformans is probably

TABLE 6

GEOGRAPHICAL DISTRIBUTION (TOTAL SERIES)

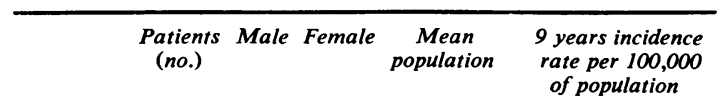

North of

Tropic of

Capricorn

South of

Tropic of

Capricorn

17

12

5365,550

$4 \cdot 7$

Total

12

8

$4 \quad 1,230,850$

0.97

-These figures represent the average of the annual mean population for the years in question. the most common cause of mycotic meningitis but, as emphasized by Greenfield, Martin, and Moore (1938) and by Cox and Tolhurst (1946), the clinical picture may closely simulate not only tuberculous meningitis but also an expanding intracranial lesion such as abscess or neoplasm.

In the present series of 29 patients with neurological cryptococcosis, there was evidence of pulmonary involvement in five instances; the adrenal gland was involved in one patient, and the prostate gland in another (Table 7). Four patients had received steroid therapy for some other disease before developing cryptococcosis: lymphosarcoma (two patients), eosinophilic granuloma (one patient) and pemphigoid skin lesions (one patient). Seven patients in this series were found to be suffering from some disorder in addition to cryptococcosis: lymphosarcoma (two patients), hepatic cirrhosis (one), histiocytosis $x$ (eosinophilic granuloma) (one), monilial stomatitis (two), pemphigoid skin lesions (one).

The two patients who had monilial stomatitis in addition to cryptococcal meningitis were siblingsa brother and sister. Both had considerable dysphagia as a result of monilial infection and needed surgical treatment for oesophageal obstruction. Their mother also had monilial infection but had never developed cryptococcosis. This family lived on a dairy farm near Rockhampton. The sister left the farm in 1956 to work as a nurse in Brisbane and developed cryptococcal meningitis in 1964. The brother left the family property in 1962 and thereafter worked on a cattle station near Rockhampton and developed cryptococcal meningitis in 1968 .

Although the onset of neurological cryptococcosis is sometimes acute, it was generally insidious and the progress slow rather than rapid. However, as will be seen from Table 8 , the diagnosis in the 24 patients in whom the disease was discovered during life was generally made within a few weeks to a month or two from the time the patient started to experience relevant symptoms. The symptoms which occurred early and late in the present series are listed in Table 9. Headache was the outstanding symptom and was often associated with nausea or vomiting. Fever was absent in some patients and in only about one-third of cases did the presence of neck stiffness suggest meningeal irritation.

Apart from papilloedema, which was not often present in the early stages, visual symptoms, other cranial nerve lesions, long tract signs, and changes in consciousness did not usually occur until late in the disease process. The typical early presentation was an adult patient complaining of increasing headaches of a few weeks' duration who did not look well. 
TABLE 7

CRYPTOCOCCAL DISEASE: STRUCTURES AFFECTED

(ASSOCIATED CONDITIONS AND THERAPY)

\begin{tabular}{|c|c|c|c|}
\hline & \multicolumn{2}{|c|}{ Patients diagnosed during life } & \multirow[t]{2}{*}{ Cases diagnosed at necropsy } \\
\hline & Clinical findings & $\begin{array}{l}\text { Necropsy findings } \\
\text { (where relevant) }\end{array}$ & \\
\hline Nervous system & 24 & 2 & 5 \\
\hline Lungs & 5 & 2 & - \\
\hline Other organs & - & - & $2\left\{\begin{array}{l}\text { adrenal toruloma } \\
\text { prostatic toruloma }\end{array}\right.$ \\
\hline Associated conditions & 7 & - & - \\
\hline Steroid therapy & 4 & - & - \\
\hline
\end{tabular}

TABLE 8

INTERVAL FROM ONSET OF SYMPTOMS TO DIAGNOSIS (CASES DIAGNOSED DURING LIFE)

\begin{tabular}{|c|c|c|c|c|}
\hline & $\begin{array}{l}\text { Patients } \\
\quad(\text { no. })\end{array}$ & $\begin{array}{c}\text { Under one month } \\
\text { (no.) }\end{array}$ & $\begin{array}{c}\text { One to six months } \\
\text { (no.) }\end{array}$ & $\begin{array}{c}\text { Six to } 12 \text { months } \\
\text { (no.) }\end{array}$ \\
\hline $\begin{array}{l}\text { North of Tropic } \\
\text { of Capricorn } \\
\text { South of Tropic }\end{array}$ & 13 & 5 & 7 & 1 \\
\hline of Capricorn & 11 & 9 & 2 & - \\
\hline Totals & 24 & 14 & 9 & 1 \\
\hline
\end{tabular}

The diagnosis of neurological cryptococcosis was usually confirmed by examination of the cerebrospinal fluid. Since cryptococcus neoformans is the only encapsulated yeast which invades the nervous system, demonstration of the oval encapsulated fungus by indian ink preparations was sufficient justification for initiating therapy while the diagnosis was being confirmed by culture and mouse inoculation.

The results of examination of the cerebrospinal

TABLE 9

CRYPTOCOCCOSIS OF NERVOUS SYSTEM SYMPTOMS AND SIGNS (29 PATIENTS)

\begin{tabular}{lcc}
\hline \multicolumn{1}{c}{ Symptoms/signs } & $\begin{array}{c}\text { Early } \\
\text { (no. of patients) }\end{array}$ & $\begin{array}{c}\text { Late } \\
\text { (no. of patients) }\end{array}$ \\
\hline Headache & 29 & 29 \\
Nausea/vomiting & 23 & 24 \\
Unsteady gait & 10 & 17 \\
Visual disturbance & 9 & 17 \\
Neck stiffness & 10 & 13 \\
Confusion & 12 & 20 \\
Fever & 11 & 12 \\
Papilloedema & 2 & 13 \\
Other cranial nerve lesions & - & 10 \\
Long tract involvement & - & 15 \\
Coma & - & 11 \\
\hline
\end{tabular}

fluid in 26 patients with neurological cryptococcosis are summarized in Table 10. It should be emphasized that in eight instances the organism could not be obtained even on repeated examination of the lumbar cerebrospinal fluid and for this reason in any suspected case the ventricular cerebrospinal fluid should be examined even in the absence of papilloedema.

TABLE 10

CEREBROSPINAL FLUID EXAMINATION (NEUROLOGICAL CRYPTOCOCCOSIS)

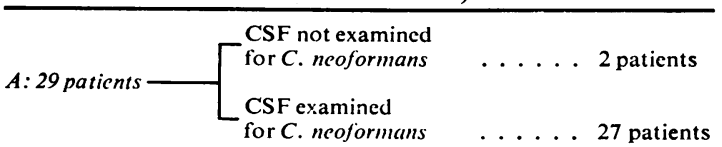

Lumbar puncture Ventricular puncture

Positive for Negative for

C.neoformans $\quad$ C.neoformans $\quad C$.ncoformans $\quad C$. neoformans

\begin{tabular}{|c|c|c|c|}
\hline 18 patients & 8 patients* & । & 1 patient \\
\hline
\end{tabular}

B: 20 patients Protein content $(\mathrm{mg} / 100 \mathrm{ml}$.)

Under $40 \quad 40-79$ 80-119 120-159 160-199 200-239 240-279 Over 283

$\begin{array}{llllllll}2 & 8 & 7 & 3 & 2 & 1 & 1 & 2\end{array}$

*These patients died without ventricular puncture being performed. 
TREATMENT

Until the introduction of amphotericin B in 1956 cryptococcal disease of the nervous system was almost invariably fatal. To exemplify this, the 14 patients previously reported from Queensland by Geaney, Horsfall, and Neilson (1956) all died from the disease. In the present series of 29 patients, 24 were diagnosed during life as having cryptococcosis of the nervous system. All these 24 patients were given amphotericin $\mathrm{B}$. Of these, as will be seen from Table 11 , only $14(58 \%)$ were known to be alive at the end of the survey period; in addition, one patient could not be traced but is believed to be alive. However, closer analysis indicates that the results of amphotericin B therapy are much better than these figures would suggest. Thus, five patients received courses of less than $230 \mathrm{mg}$ amphotericin B and cannot therefore be regarded as having received adequate treatment. Of 19 patients who received adequate treatment with amphotericin B, $14(73.7 \%)$ were known to be alive at the end of the survey period. One further patient was believed to be alive but could not be traced, and of the four deceased patients in this group one patient died from lymphosarcoma six years after the cryptococcal infection had been cured. Thus the survival rate of these 19 patients adequately treated with amphotericin B was about $84 \%$.

\section{TABLE 11}

SURVIVAL IN 24 PATIENTS DIAGNOSED DURING LIFE AS SUFFERING FROM CRYPTOCOCCOSIS OF NERVOUS SYSTEM AND TREATED WITH AMPHOTERICIN B

\begin{tabular}{lccc}
\hline & Male & Female & Total \\
\hline $\begin{array}{l}\text { Alive October 1968 } \\
\text { Deceased by October } 1968\end{array}$ & 10 & 4 & 14 \\
$\begin{array}{l}\text { Not traced } \\
\text { (believed to be alive) }\end{array}$ & 1 & $2 *$ & 9 \\
Totals & 18 & 6 & 24 \\
\hline
\end{tabular}

*Including one patient who died from lymphosarcoma-no evidence of active cryptococcosis.

The survival times of the 14 patients regarded as having been adequately and successfully treated, but not including the patient who could not be traced, are indicated in Table 12A. The survival times of those patients who were adequately treated yet died from cryptococcosis are shown in Table $12 B$.

Amphotericin B may be administered intravenously or intrathecally. The routes of administration and the outcome in the 19 patients who received adequate therapy are indicated in Table 13. It
TABLE 12

SURVIVAL TIMES

\begin{tabular}{lccccccccc}
\hline & \multicolumn{1}{c}{ A: Survival times of successfully treated cases } \\
Years & -2 & -3 & -4 & -5 & -6 & -7 & $8+$ & Total \\
\cline { 2 - 9 } & & -2 & 1 & 2 & 4 & 1 & $3 *$ & 2 & 15
\end{tabular}

B: Survival times of patients who died by October 1968

\begin{tabular}{|c|c|c|c|}
\hline \multicolumn{4}{|c|}{ from cryptococcosis } \\
\hline Years & Under 1 & Under 3 & Total \\
\hline atents (no.) & 2 & 1 & 3 \\
\hline
\end{tabular}

*Including one patient who died from lymphosarcoma. One patient known to be alive seven months after therapy and believed to be still alive but not traced-not included in this Table.

TABLE 13

AMPHOTERICIN B THERAPY: ROUTE OF ADMINISTRATION AND RESULTS OF THERAPY

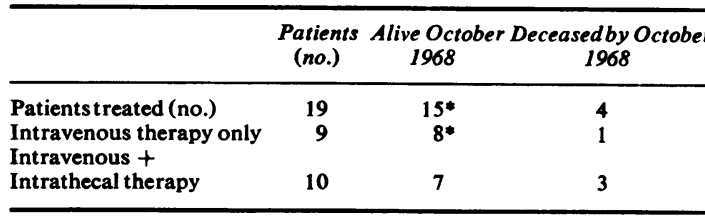

*Including one patient not traced but believed to be alive.

appears that intravenous therapy alone can b successful, but in seriously ill patients both intravenous and intrathecal routes should be used. The three patients who died from cryptococcosis were given amphotericin $B$ intravenously and intrathe cally but it is probable that the fatal outcome is a reflection of the serious state they were in at the time of treatment rather than an indication of increased toxicity of the drug when given intrathecally.

Amphotericin B is given by intravenous infusion in a dose of $1 \mathrm{mg} / \mathrm{kg}$ of body weight in a $5 \%$ solution of dextrose in water, over a period of six hours, daily or every second day, for a period of six weeks to three months. It is generally advisable to commence treatment with $1 \mathrm{mg}$ in $250 \mathrm{ml} .5 \%$ dextrose and thereafter to increase the dose by 5 to $10 \mathrm{mg}$ each day (at the same time increasing the volume of $5 \%$ dextrose) until $1 \mathrm{mg} / \mathrm{kg}$ of body weight is being given (Andrioli and Krauetz, 1962). For intrathecal administration of amphotericin B, lumbar puncture is performed and $5 \mathrm{ml}$. cerebrospinal fluid are withdrawn into an appropriate syringe. The fluid is mixed with 15 to $20 \mathrm{mg}$ hydrocortisone and is then slowly injected intrathecally. Several minutes later $5 \mathrm{ml}$. cerebrospinal fluid may again be withdrawn and mixed with $2.5 \mathrm{ml}$. of a solution containing 0.25 to $0.5 \mathrm{mg}$ amphotericin $B$ in $5 \%$ glucose and water. This mixture is then slowly 
injected into the lumbar subarachnoid space. The procedure may be repeated two or three times each week until a total of $15 \mathrm{mg}$ amphotericin B has been given intrathecally.

Although amphotericin $B$ is effective in the treatment of this otherwise fatal condition, sideeffects of the drug are commonly encountered. Table 14 lists the side-effects which occurred in the 19 patients who received adequate therapy. Fortunately, many of these adverse reactions are self limiting or can be minimized by employing a smaller dosage of the drug, by slowing the drip rate, and by the concurrent use of steroids or antihistamine drugs. The blood urea rose to between $80 \mathrm{mg}$ and $116 \mathrm{mg} / 100 \mathrm{ml}$. in all cases, but at the time of the end of the survey period (October 1968) the blood urea remained elevated in only one patient whose blood urea had been elevated in similar degree before receiving amphotericin B therapy. Routine serum potassium estimations were not performed in all cases. In two patients, however, serum potassium was diminished during treatment but later reverted to normal. In this series no permanent damage appears to have been inflicted by the drug on the kidneys as judged by clinical examination and the relatively crude tests of examination of the urine for protein and blood urea estimations. Similarly, liver and haemopoetic tissues appeared to escape serious insult.

\section{TABLE 14}

SIDE EFFECTS OF AMPHOTERICIN B THERAPY (19 PATIENTS)

\begin{tabular}{lc}
\hline Symptoms & Patients (no.) \\
\hline Nausea/vomiting & 10 \\
Rigors & 13 \\
Muscle pain & 1 \\
Skin rash & 2 \\
Thrombophlebitis & 3 \\
Tremor of hands & 3 \\
Hypotension & 1 \\
\hline
\end{tabular}

\section{DISCUSSION}

The sex incidence in this series (20 males : nine females) reflects the opinion generally held that men are more frequently affected than women (Littman and Walter, 1968). These authors also refer to two-thirds of patients being between the ages of 30 and 50 years and in the present series $79 \%$ developed the disease between 20 and 59 years of age. The disease is uncommon in the first decade of life and our only patient in this age group, an aboriginal boy aged 8 years, is the youngest patient in our experience. Thus, in the 14 cases of cryptococcosis previously reported from Queensland (Geaney et al.,
1956) the youngest patient was an aboriginal boy aged 15 years and in 14 cases from South Africa analysed by Gear and Newton (1969) only one child, an African aged 9 years of age, suffered from cryptococcosis of the nervous system, while another 9-year-old African child had femoral osteitis from which C. neoformans was isolated (Bubb, 1955). Our fiindings are thus in agreement with the opinion expressed by Brody (1969) that the majority of patients suffering from neurological cryptococcosis are adult males.

In the present survey, 20 of the 29 patients were regarded as having outdoor occupations and of these 12 worked with livestock (cattle) or poultry. Because $C$. neoformans has been recovered from soil and from various animals and birds, it seemed possible that occupational exposure could be an important link in the chain of aetiology. McCall (1969) pointed out that the age distribution in this and in other series would favour an occupational risk rather than a soil reservoir of infection, which would have been more readily incriminated had the majority of patients been in the first decade of life. Although Littman and Zimmerman (1956) felt that occupation seemed to play little part in the incidence of the disease, in a later paper Littman and Walter (1968), emphasizing the high prevalence of the fungus in the excreta of domesticated and feral pigeons, felt that it was not unreasonable to consider cryptococcosis as an occupational hazard. $C$. neoformans is certainly found in the soil (Emmons, 1955; MacGillivray, 1964) and in the excreta of birds, especially pigeons (Littman and Schneierson, 1959; Frey and Durie, 1964); the fungus has been recovered from various animals (Littman and Zimmerman, 1956), including cattle (Simon, Nichols, and Morse, 1953) and even the koala (Bolliger and Finckh, 1962). In view of this widespread distribution in nature, it is probable that many people inhale the fungus without ill effects (Annotation, Lancet, 1969) and Cox and Tolhurst (1946) considered it was possible that individual susceptibility or resistance might play an important role. This concept is supported by the concurrence of cryptococcosis of the nervous system with other disorders which might disturb immune responses (Zimmerman and Rappaport, 1954) and with long-continued steroid therapy which, in a similar way, also predisposes the individual to infection (Goldstein and Rambo, 1962). In the present series, seven patients suffered from a disease in addition to cryptococcosis and four patients were receiving steroid therapy when they developed evidence of the infection. It is, however, considered possible that clinical cryptococcosis may also result from repeated exposure to the infection or to individual exposure to an 
overwhelming infection and that rural residence and occupation may be important in this regard.

Littman and Zimmerman (1956) considered that there was no greater susceptibility to cryptococcosis in dark-skinned races than in white-skinned races, and Littman and Walter (1968) suggested that pulmonary cryptococcosis appeared to have a marked predilection for the white man. However, in Australia, four of the 14 patients reported by Geaney et al. (1956) were aboriginals and Crotty (1965) considered that 0.5 to $1 \%$ of deaths in aboriginals in the Northern Territory resulted from cryptococcal meningitis. In the present series of 29 patients, five were coloured, furnishing a nine years incidence rate of 25.9 per 100,000 compared with 1.5 per 100,000 for those of European extraction. We are indebted to Gear and Newton (1969) who furnished us with the following information from South Africa: they encountered 14 patients with cryptococcosis in the South African literature, and in their own experience, of whom five were European, seven African, one 'coloured', and one Indian.

It is established that neurological cryptococcosis occurs in dark and white races and that in Queensland there is a relatively high incidence of the disease in the aboriginal as well as the white population. The possibility that the higher incidence in the aboriginal can be correlated with geographical and occupational factors needs further study, especially as the aboriginal population tends to live in country districts and work at rural occupations in the north and west of the State.

Reference has already been made to the fact that cryptococcosis of the nervous system would appear to be more common in Australia than in the United Kingdom, although the population of Australia is predominantly of British stock. Cases reported in the Australian literature from 1935 to the present time are indicated in Table 15 . This should not be taken to indicate the prevalence of the disease in the various states but it does suggest a relatively high incidence of cryptococcosis, an incidence which cannot be wholly accounted for by a possible increased susceptibility in the Australian aboriginal. The results of the present survey also indicate that neurological cryptococcosis is more prevalent in tropical north Queensland than in the more temperate south, so that of the 29 patients in the series, 17 were living in the north when they developed the disease (a nine years incidence rate of 4.7 per 100,000 ) compared with a nine year incidence rate of 1.8 per 100,000 in South Queensland. The geographical features of cases reported by Geaney et al. (1956) in Queensland was very similar in that at least six of their 14 patients acquired the disease in the north
TABLE 15

CASES OF CRYPTOCOCCOSIS REPORTED FROM AUSTRALIA (1935-1969)

\begin{tabular}{|c|c|c|}
\hline State or territory & $\begin{array}{l}\text { Cases } \\
\text { (no.) }\end{array}$ & Author(s) \\
\hline Queensland & $\begin{array}{r}14 \\
1 \\
29\end{array}$ & $\begin{array}{l}\text { Geaney et al. (1956) } \\
\text { Kuo (1962) } \\
\text { Present series }\end{array}$ \\
\hline New South Wales & $\begin{array}{r}1 \\
1 \\
1 \\
1 \\
7 \\
27\end{array}$ & $\begin{array}{l}\text { Sawers and Thompson (1935) } \\
\text { Piper (1944) } \\
\text { Rothfield (1945) } \\
\text { Alderman (1949) } \\
\text { Hickie and Walker (1964) } \\
\text { Allsop, McLeod, and Gye (1969) }\end{array}$ \\
\hline Victoria & $\begin{array}{r}13 \\
2\end{array}$ & $\begin{array}{l}\text { Cox and Tolhurst (1946) } \\
\text { Buckle and Curtis (1955) }\end{array}$ \\
\hline South Australia & $\begin{array}{l}2 \\
8\end{array}$ & $\begin{array}{l}\text { Champion de Crespigny (1944) } \\
\text { Wilson (1958) }\end{array}$ \\
\hline Western Australia & $\begin{array}{r}2 \\
13\end{array}$ & $\begin{array}{l}\text { Fortune, Donnan, Colebatch, and } \\
\text { Lubbe (1955) } \\
\text { Keale, Wilkie, and Binns (1968) }\end{array}$ \\
\hline Northern Territory & 10 & Crotty (1965) \\
\hline
\end{tabular}

of the State. These authors also refer to two of their patients (aboriginals) coming from the same mission station near Cairns and a third aboriginal patient derived from a settlement, near Rockhampton, as did a fourth patient not included in their series. Numbers are too few to allow one to speak of 'pockets' of infection but the geographical distribution of cases in the present series might indicate areas in North Queensland where there is a relatively high incidence of the disease. The importance of a high environmental exposure to the fungus was also suggested by Muchmore, Rhoades, Nix, Felton, and Carpenter (1963) who found a high occurrence of $C$. neoformans in the environment of three geographically associated patients suffering from cryptococcal meningitis in a population of 3,204 people residing near a bird sanctuary. Available evidence would suggest that in Australia there is an animal, rather than a bird, reservoir of the fungus, and that occupational exposure and dry, dusty conditions which would predispose to massive inhalation of $C$. neoformans, are important factors in the aetiology of the disease. Individual susceptibility, perhaps racial, probably plays a part and, as in other regions, development of the clinical disease is predisposed to by disorders such as the reticuloses or by long-continued steroid therapy.

Cryptococcosis of the nervous system may present clinically with symptoms suggestive of cerebral neoplasm, cerebral abscess, chronic subdural haematoma, chronic meningitis of any variety including tuberculosis and brucellosis, sarcoidosis, neurosyphilis, lymphocytic choriomeningitis, leu- 
kaemic infiltration of meninges and meningeal carcinomatosis. Further, the neurological disorder may be obscured by an associated coexistent disease such as one of the reticuloses, leukaemia, or diabetes mellitus (Zimmerman and Rappaport, 1954; Littman and Walter, 1968). In our experience, clinical evidence of meningitis occurred in only one-third of the cases. Similarly, fever may be inconspicuous throughout the illness. Headache of insidious onset, sometimes intermittent in the early stages, but becoming continuous and progressively more severe, is the outstanding symptom, and a patient 'who does not look well', the outstanding physical sign.

In a patient suspected of having neurological cryptococcosis, the diagnosis is established by identifying $C$. neoformans in the cerebrospinal fluid by indian ink examination and subsequently by culture and mouse inoculation. Serological antibody tests have been devised but, since $C$. neoformans may lead a saprophytic existence in the lungs and elsewhere and since these tests have furnished negative results despite the known presence of the fungus, they must be regarded as being of doubtful value at the present time. The only proof of active disseminated cryptococcal infection is the demonstration of the fungus in the cerebrospinal fluid, blood or urine (Annotation, Lancet, 1969).

Our experience, however, suggests that $C$. neoformans may be difficult to detect in the lumbar cerebrospinal fluid even in patients with active or advanced involvement of the nervous system. Thus, in five patients we were unable to detect the fungus even on repeated examinations of the lumbar cerebrospinal fluid, the organism being identified, however, on direct examination of the ventricular cerebrospinal fluid. It is therefore suggested that in any suspected case-and perhaps particularly since an intracranial expanding lesion so often enters into the differential diagnosis-ventriculography with examination of the cerebrospinal fluid by indian ink technique (and culture) at the same time, is the most efficient way of establishing the correct diagnosis.

Although it has been correctly suggested that amphotericin B therapy should be withheld until there is evidence that cryptococcal infection has become disseminated (Tynes, Mason, Jennings, and Bennett, 1968; Warr, Bates, and Stone, 1968), it must be emphasized that neurological cryptococcosis is evidence of disseminated infection and constitutes a definite indication for amphotericin B therapy. The fact that the drug is expensive, its administration unpleasant for the patient and for the doctor, and involves a prolonged regime of careful surveillance, does not detract from the value of amphotericin B, which is the only effective therapy for neurological cryptococcosis at the present time. Spickard, Butler, Andriole, and Utz (1963), in a series of 30 patients, reported $53 \%$ cured after one course of treatment and a further $30 \%$ were successfully treated after a relapse. In the present series of 19 patients who received adequate treatment, 14 $(73.7 \%)$ were known to be alive at the end of the survey period; a further patient who could not be traced was believed to be alive, and one other patient died from lymphosarcoma six years after the cryptococcal infection had been eradicated. It is therefore considered that a cure rate of approximately $80 \%$ can be expected in patients suffering from neurological cryptococcosis who are diagnosed and adequately treated at a reasonably early stage in the disease process.

Before the introduction of amphotericin B, the outlook in neurological cryptococcosis was almost uniformly hopeless. Cox and Tolhurst (1946) considered that 'nothing is known that influences its course favourably' and Littman and Zimmerman (1956) believed that 'permanent cures are extremely rare if obtained at all'. The one hundred per cent mortality in the 14 patients reported from Queensland before amphotericin B was available (Geaney et al., 1956) supports these views.

Despite the suggestion that amphotericin B given intravenously in safe dosage does not achieve significant drug levels in the cerebrospinal fluid (Rubin and Furcolow, 1958), seven of the nine patients thus treated in this series were alive and well at the end of the survey period and another patient was believed to be alive but could not be traced. The present findings are in agreement with the views of Witorsch, Williams, Ommaya, and Utz (1965) that many and perhaps the majority of patients suffering from cryptococcal meningitis require only intravenous therapy. Intrathecal administration of amphotericin B should be reserved for cases in relapse or for those who are critically ill from the disease when first seen. In such cases, the drug can be given by lumbar or cisternal puncture or, if available, the Ommaya reservoir which permits of repeated intraventricular administration would seem to have much to commend it (Ommaya, 1963; Witorsch et al., 1965).

Although in this series of patients side-effects of amphotericin B therapy occurred in more than half of the 19 patients who received adequate treatment, these can be minimized by employing smaller doses of the drug, by reducing the rate of administration, by giving the drug on alternate days as suggested by Battock, Grausz, Bobrowsky, and Littman (1968), and by the concurrent use of steroids or an antihistamine. The blood urea became elevated in all 
cases during treatment but as previously indicated there was no clinical or laboratory evidence of permanent damage to kidneys, liver, or the haemopoetic system at the end of the survey period. However, our tests of liver function were relatively insensitive and, as shown by McCurdy, Frederic, and Elkington (1968), a tubular defect in acid excretion superimposed on a kidney rendered ischaemic by renal vasoconstriction appears to underlie the hypokalaemia and nephrocalcinosis characteristic of amphotericin B nephropathy.

Two further factors merit consideration in the treatment of neurological cryptococcosis. In a number of patients an underlying associated disease such as Hodgkin's disease, reticulosis, leukaemia, or diabetes mellitus may be present. These conditions which require their own specific treatment may, of course, materially alter the outcome of the case. Secondly, complications of chronic meningitis may develop. Thus, Lethlean and Gye (1969) have emphasized the importance of considering a diagnosis of occult (low pressure) hydrocephalus as a possible explanation for continuing headaches, gait disturbances, and failing intellectual status during the course of treatment in a patient suffering from cryptococcal meningitis or subsequent to apparent cure. In such cases a ventriculo-atrial shunt may prove most rewarding.

It is a pleasure to acknowledge the very great help we have received from our colleagues without whose assistance this survey could not have been conducted. We are particularly indebted to Dr. Ivan Lester and Dr. R. Spooner (Cairns), Dr. R. A. Douglas and Dr. A. D. Campbell (Townsville), Dr. Sale and Dr. Learmonth (Rockhampton), and to their registrars and records officers. We are also grateful to the doctors at the various other major hospitals who provided us with information essential to the survey, and to Mr. S. E. Solomon, Commonwealth Bureau of Census and Statistics, Queensland Office, for his assistance. This survey was supported by a grant from E. R. Squibb \& Sons Pty. Ltd., whose preparation of amphotericin B (Fungizone) was employed in the treatment of our patients. We are grateful for this support and to Dr. A. C. Jenkins, Australian medical director of that firm, for his help and encouragement.

\section{REFERENCES}

Alderman, L. W. (1949). Report on a case of cerebro-spinal meningitis due to cryptococcosis histolytica (torula hominis). Med.J. Aust., 2, 914-916.

Allsop, J. L., McLeod, J. D., and Gye, R. S. (1969). Meeting, Australian Association of Neurologists, Brisbane, May 1969.

Andrioli, V. T., and Kravetz. H. M. (1962). The use of Amphotericin B in man. J. Amer. med. Ass., 180, 269. 272.
Battock, D. J., Grausz, H., Bobrowsky, M., and Littman, M. L. (1968). Alternate-day Amphotericin B therapy in the treatment of rhinocerebral phycomycosis (mucormycosis). Ann. int. Med., 68, 122-137.

Bolliger, A., and Finckh, E. S. (1962). The prevalence of cryptococcus in the koala (phascolarctos cinereus). Med.J. Aust., 1, 545-547.

Brody, J. A. (1969). Personal communication.

Bubb, H. (1955). Cryptococcus neoformans infection in bone. S. Afr. med.J., 29, 1259-1261.

Buckle, G., and Curtis, D. R. (1955). Therapy of human torulosis with actidione and 'contramine': a report on two cases. Med. J. Aust., 2, 854-859.

Champion de Crespigny, C. T. (1944). Torula infection of the central nervous system. Med. J. Aust., 2, 605-615.

Cox, L. B., and Tolhurst, J. C. (1946). Human Torulosis, a Clinical, Pathological and Microbiological Study; with a Report of Thirteen Cases. Melbourne University Press: Melbourne.

Crotty, J. M. (1965). Systemic mycotic infections in northern territory aborigines. Med. J. Aust., 1, 184-186.

Emmons, C. W. (1955). Saprophytic sources of cryptococcus neoformans associated with the pigeon (Columba livia). Amer.J. Hyg., 62, 227-232.

Fortune, C., Donnan, G., Colebatch, J., and Lubbe, T. (1955). Torulosis. Med. J. Aust., 2, 199-204.

Frey, D., and Durie, E. B. (1964). The isolation of cryptococcus neoformans (Torula Histolytica), from soil in New Guinea and pigeon droppings in Sydney, New South Wales. Med. J. Aust., 1, 947-949.

Geaney, B., Horsfall, W. R., and Neilson, G. (1956). Torulosis in Queensland: report of fourteen cases. Med. J. Aust., 2, 378-382.

Gear, J. H. S., and Newton, P. (1969). Personal communication.

Goldstein, E., and Rambo, O. N. (1962). Cryptococcal infection following steroid therapy. Ann. int. Med., 56, 114-120.

Greenfield, J. G., Martin, J. P., and Moore, M. T. (1938). Meningo-encephalitis due to cryptococcus meningitidis (torula histolytica) with report of case. Lancet, 2, 11541157.

Hickie, J. B., and Walker, T. (1964). Cryptococcosis (Torulosis): Some problems in diagnosis and management. Aust. Ann. Med., 13, 229-239.

Keale, D. D., Wilkie, J. A., and Binns, C. (1968). Cryptococcosis: a survey in Western Australia. Med. J. Aust., 2, 665-668.

Kuo, D. (1962). A case of torulosis of the central nervous system during pregnancy. Med.J. Aust., 1, 558-560.

Lancet (1969). When is the cryptococcus dangerous? Annotation, 1, 820-821.

Lethlean, K., and Gye, R. (1969). Dementia in the adult due to occult hydrocephalus. Proc. Aust. Ass. Neurol., 6, 13-19.

Littman, M. L., and Schneierson, S. S. (1959). Cryptococcus neoformans in pigeon excreta in New York City. Amer. J. Hyg., 69, 49-59.

Littman, M. L., and Zimmerman, L. E. (1956). Cryptococcosis, Torulosis, or European Blastomycosis. Grune and Stratton: New York.

Littman, M. L., and Walter, J. E. (1968). Cryptococcosis: current status. Amer.J. Med., 45, 922-932.

McCall, M. (1969). Personal communication.

MacGillivray, J. B. (1966). Two cases of cryptococcosis. J. clin. Path., 19, 424-428.

McCurdy, D. K., Frederic, M., and Elkington, J. R. (1968). New Engl. J. Med., 278, 124-130. 
Muchmore, H. G., Rhoades, E. R., Nix, G. E., Felton, F. G., and Carpenter, R. E. (1963). Occurrence of cryptococcus neoformans in the environment of of three geographically associated cases of cryptococcal meningitis. New Engl. J. Med., 268, 1112-1114.

Ommaya, A. K. (1963). Subcutaneous reservoir and pump for sterile access to ventricular cerebrospinal fluid. Lancet, 2, 983-984.

Piper, J. E. (1944). A case of torulosis. Med. J. Aust., 1, 441.

Rubin, H., and Furcolow, M. L. (1958). Promising results in cryptococcal meningitis. Neurology (Minneap.), 8, 590-595.

Rothfield, R. D. (1945). Torulosis involving the brain and its membranes. Med.J. Aust., $2,90$.

Sawers, W. C., and Thomson, E. F. (1935). Torulosis, with a report of a case of meningitis due to torula histolytica. Med.J. Aust., 2, 581-593.

Simon, J., Nichols, R. E., and Morse, E. V. (1953). An outbreak of bovine cryptococcosis. J. Amer. vet. med. Ass., 122, 31-35.
Spickard, A., Butler, W. T., Andriole, V., and Utz, J. P. (1963). The improved prognosis of cryptococcal meningitis with Amphotericin B therapy. Ann. int. Med., 58, 66-83.

Tynes, B., Mason, K. N., Jennings, A. E., and Bennett, J. E. (1968). Variant forms of pulmonary cryptococcosis. Ann. int. Med., 69, 1117-1125.

Warr, W., Bates, J. H., and Stone, E. A. (1968). The spectrum of pulmonary cryptococcosis. Ann. int. Med., 69, 11091116.

Wilson, L. L. (1958). Cryptococcosis (torulosis): a report of nine cases. Aust. Ann. Med., 7, 276-285.

Witorsch, P., Williams, T. W. Jun., Ommaya, A. K., and Utz, J. P. (1965). Intraventricular administration of Amphotericin B. Use of subcutaneous reservoir in four patients with mycotic meningitis. J. Amer. med. Ass., 194, 699-702.

Zimmerman, L. E., and Rappaport, H. (1954). Occurrence of cryptococcosis in patients with malignant disease of reticuloendothelial system. Amer. J. clin. Path., 24, 1050-1072. 